\title{
A EFETIVAÇÃO DOS DIREITOS FUNDAMENTAIS À LUZ DE CANOTILHO E DE ALEXY
}

\author{
Fabrício Wloch ${ }^{349}$ \\ Carlos Roberto da Silva ${ }^{350}$
}

Recebido em: 21/11/2016

Aprovado em: 03/06/2017

\section{RESUMO}

Este artigo científico investiga como os estudos do jurista português José Joaquim Gomes Canotilho e do jurista alemão Robert Alexy podem contribuir para a efetivação dos Direitos Fundamentais previstos na atual Constituição da República Federativa do Brasil. Apesar de positivados da Constituição, a efetividade dos Direitos Fundamentais depende da interpretação e aplicação dada pelos operadores jurídicos, daí exsurge a importância da contribuição de ambos os autores, já que enfrentam os mesmos problemas na Constituição de seus países. Na primeira parte caracterizou-se a positivação dos Direitos Fundamentais na atual Constituição da República Federativa do Brasil. Na segunda tratou-se da aproximação do tema com o princípio democrático desenvolvido por Canotilho. Na terceira parte abordou-se a teoria dos Direitos Fundamentais de Alexy. Concluiu-se com a adaptação das principais ideias de ambos à realidade brasileira de modo a contribuir para a efetivação dos Direitos Fundamentais no país. A pesquisa justifica-se pela importância da temática para a contemporaneidade, mormente pela necessidade de efetivação dos Direitos Fundamentais. $\mathrm{O}$ trabalho foi desenvolvido sob método indutivo. A pesquisa foi bibliográfica e documental.

Palavras-chave: Direitos Fundamentais. Efetividade. Regras. Princípios. Democracia.

\section{INTRODUÇÃO}

\footnotetext{
349 Doutorando e Mestre em Ciência Jurídica do Programa de Pós-Graduação Stricto Sensu em Ciência Jurídica pela Universidade do Vale do Itajaí - Univali.

${ }^{350}$ Doutor em Direito pela Universidade de Alicante/Espanha e Doutor em Ciência Jurídica pela Universidade do Vale do Itajaí - Univali. Desembargador do Tribunal de Justiça do Estado de Santa Catarina.
} 
Este artigo científico tem como objeto os Direitos Fundamentais da Constituição da República Federativa do Brasil. O objetivo é descrever as contribuições do jurista português Canotilho e do jurista alemão Alexy para a efetivação de tais direitos, já que ambos os analisam e a forma de efetivá-los com base nas Constituições de seus países.

O problema enfrentado é que, apesar de estarem positivados na Constituição da República Federativa do Brasil, as normas de Direitos Fundamentais não são efetivas, ou seja, ainda pecam em gerar resultados verdadeiros para os cidadãos brasileiros.

Parte-se da hipótese de que a efetividade dos Direitos Fundamentais depende essencialmente da interpretação e aplicação dada pelos operadores jurídicos, no que Canotilho e Alexy podem contribuir, haja vista que o primeiro cuida de conectar os Direitos Fundamentais essencialmente com os mecanismos da democracia; e o segundo trabalha a fórmula da ponderação no caso de conflito de regras e de colisão de princípios que envolvem os Direitos Fundamentais.

Na primeira fase da pesquisa - a decisão - operou-se com o referente (PASOLD, 2015, p. 57-66) de investigar quais as contribuições de Canotilho e Alexy para a efetivação dos Direitos Fundamentais no Brasil. Na segunda fase - a busca de dados - garimparam-se fundamentos doutrinários sob o método indutivo (op. cit., p. 104). Na terceira fase de pesquisa - de tratamento de dados recolhidos - foram correlacionadas sob o método cartesiano (DESCARTES, 1999, p. 23) as formulações recolhidas em função do referente eleito. A quarta fase da pesquisa culminou neste relatório de pesquisa, que aponta as conclusões.

Inicialmente, abordou-se a ideia de Constituição e de Direitos Fundamentais, destacando a importância da Carta Magna, bem como a força normativa por ela exercida sobre as demais áreas do Direito. Na segunda parte, descreveram-se as bases teóricas de Canotilho. Na terceira parte, versou-se a respeito da teoria dos Direitos Fundamentais de Alexy. Na quarta destacou-se a possibilidade de efetivação dos Direitos Fundamentais sob a perspectiva de ambos.

No que se refere à metodologia (PASOLD, 2015, p. 85), este trabalho concentrou-se na área de Estado, Transnacionalidade e Sustentabilidade, foi desenvolvido sob o método indutivo e cartesiano e operacionalizado com as técnicas do referente, da categoria, do conceito operacional mediante pesquisa bibliográfica e documental. 
A Constituição representa para o Estado a norma de maior importância dentre as normas do ordenamento jurídico, por essa razão é também chamada de Carta Magna. Trata-se de uma compilação de normas abrangentes, que englobam Direitos Fundamentais inerentes ao indivíduo e normas de organização dos poderes do Estado, constituindo-se como uma “expressão jurídica do enlace entre o poder e a comunidade política ou entre governantes e governados" (MIRANDA, 2011, p. 157).

Ao discorrer acerca do tema, Canotilho (2003, p. 52-53) apresenta dois aspectos diferenciados, a partir dos quais se pode compreender a forma de estruturação da Constituição, sendo eles, a Constituição moderna e a Constituição histórica:

\footnotetext{
Por constituição moderna entende-se a ordenação sistemática e racional da comunidade política através de um documento escrito no qual se declaram as liberdades e os direitos e se fixam os limites do poder político. [...] Por constituição em sentido histórico entender-se-á o conjunto de regras (escritas ou consuetudinárias) e de estruturas institucionais conformadoras de uma dada ordem jurídico-política num determinado sistema político social.
}

Vê-se que a Constituição tanto sob o aspecto moderno quanto histórico, apresenta-se como fundamental à organização da sociedade, de modo que se pode inferir que a "Constituição se refere não apenas ao Estado, mas à própria comunidade política, ou seja, à res publica" (CANOTILHO, 2003, p. 88).

A Constituição significa para o Estado e para a sociedade a norma que confere poder e direitos aos indivíduos em sociedade, ao mesmo tempo em que pauta a atuação do Estado.

A Constituição, portanto, cria ou reconstrói o Estado, organizando e limitando o poder
político, dispondo acerca de Direitos Fundamentais, valores e fins públicos e
disciplinando o modo de produção e os limites de conteúdo das normas que integrarão
a ordem jurídica por ela instituída. Como regra geral, terá a forma de um documento
escrito e sistemático, cabendo-lhe o papel, decisivo no mundo moderno, de transportar
o fenômeno político para o mundo jurídico, convertendo o poder em Direito
(BARROSO, 2011, p. 98).

Destaca Barroso (ibidem) que "a Constituição é um instrumento do processo civilizatório. Ela tem por finalidade conservar as conquistas incorporadas ao patrimônio da humanidade e avançar na direção de valores e bens jurídicos socialmente desejáveis e ainda não alcançados".

Nesse sentido, observa-se que a Constituição da República Federativa do Brasil de 1988 significou um grande avanço normativo em relação a sua antecessora ou mesmo a suas antecessoras, haja vista que apresentou à sociedade maiores garantias e direitos aos indivíduos. 
Chamada de Constituição Cidadã, trouxe uma gama de direitos e garantias individuais fundamentais, além de normas que se apresentaram como uma forma de impor de limitações ao poder do Estado.

Logo, os Direitos Fundamentais, tais como postos atualmente no ordenamento jurídico brasileiro, passaram a ser melhor difundidos com o advento da Constituição da República Federativa do Brasil de 1988, que reservou espaço de destaque aos direitos e garantias fundamentais (BRASIL, 1988, art. 5º).

Para efeito deste estudo, delimitam-se os Direitos Fundamentais aos enunciados no art. $5^{\circ}$ da Constituição da República Federativa do Brasil e também outros decorrentes do regime e dos princípios por ela adotados, ou dos tratados internacionais em que a República seja parte, conforme expresso no $\S 3^{\circ}$.

Pode-se, assim, dizer que "na tradição do constitucionalismo democrático, as necessidades e os interesses vitais das pessoas estipuladas como merecedoras de tutela têm sido expressados quase sempre sob a forma de Direitos Fundamentais" (FERRAJOLI, 2010, p. 2973).

E que, apesar de certos direitos serem inerentes ou naturais aos indivíduos, a sua existência por si só não garante a sua não agressão havendo a necessidade de tê-los como Direitos Fundamentais positivados.

Há, contudo, que se destacar, que os Direitos Fundamentais de liberdade, sobrevivência, saúde, integridade, e todos os outros valores tidos como essenciais aos indivíduos, não foram assegurados tão somente com o advento de uma Constituição democrática no Estado. Foram, pelo contrário, "inicialmente reivindicados, e posteriormente reconhecidos e tutelados através da atribuição aos indivíduos, de expectativas, ou de pretensões ou faculdades concebidas sempre como direitos subjetivos" (ibidem).

Apesar do patamar para o qual foram erigidas as normas que versam acerca de Direitos Fundamentais, verifica-se que sua aplicabilidade e efetividade encontram limitações.

Há um conflito frente aos aspectos da Constituição, haja vista que se a Constituição, na qual estão positivados os Direitos Fundamentais é a norma fundamental do Estado - a Carta Magna -, as normas constantes de seu texto legal deveriam ser imperativamente seguidas em todas as demais áreas do Direito, bem como deveriam ser uma forma de orientação de governantes e governados. Isso porque "as normas constitucionais são dotadas de imperatividade, que é atributo de todas as normas jurídicas, e sua inobservância há de deflagrar mecanismos próprios de coação, de cumprimento forçado" (BARROSO, 2007). 
Nesse sentido, Bobbio (2004, p. 23) destaca que a problemática envolvendo os Direitos Fundamentais e direitos dos homens não está na busca de novos fundamentos para sua aplicação e, sim, lhes proporcionar eficácia, pois "o problema fundamental em relação aos direitos do homem, hoje, não é tanto o de justificá-los, mas o de protegê-los. Trata-se de um problema não filosófico, mas político".

Contudo, verifica-se que o positivismo jurídico, não apenas a Constituição, apresentase em crise, de tal forma que esta não exerce sua força normativa. Não há primazia pelos valores constitucionais na aplicação do Direito ao caso concreto.

Nas palavras de Hesse (1991, p. 21):

A Constituição não deve assentar-se numa estrutura unilateral, se quiser preservar a
sua força normativa num mundo em processo de permanente mudança político-social.
Se pretende preservar a força normativa dos seus princípios fundamentais, deve ela
incorporar, mediante meticulosa ponderação, parte da estrutura contrária. Direitos
Fundamentais não podem existir sem deveres, a divisão de poderes há de pressupor a
possibilidade de concentração de poder, o federalismo não pode subsistir sem uma
certa dose de unitarismo.

Observa-se, assim, que contrariamente ao posicionamento de Lassalle (1998), para o qual a Constituição significa apenas uma folha de papel, Hesse destaca que a Constituição deve ser interpretada conforme as mudanças sociais, de modo que "uma mudança das relações fáticas pode - ou deve - provocar mudanças na interpretação da Constituição" (HESSE, 1991, p. 23).

Nesse âmbito, em que pese a crise do ordenamento jurídico, não se pode deixar de mencionar que a atual Constituição brasileira exerce grande influência sobre as demais normas infraconstitucionais. Pode-se caracterizar a Constituição da República Federativa do Brasil como sendo a "morada da justiça, da liberdade, dos poderes legítimos, o paço dos Direitos Fundamentais, portanto, a casa dos princípios, a sede da soberania” (BONAVIDES, 2004).

Contudo, apesar da soberania da Constituição sobre as demais normas infraconstitucionais, verifica-se que a efetiva aplicação da Constituição, i.e., que a efetividade dos direitos constitucionalmente tutelados, não alcançou o patamar de "normas constitucionais de eficácia plena”, estas entendidas como ensina Silva (1998, p. 91-101):

Normas de eficácia plena são "aquelas que, desde a entrada em vigor da constituição, produzem, ou têm possibilidade de produzir, todos os efeitos essenciais, relativamente aos interesses, comportamentos e situações que o legislador constituinte, direta ou indiretamente, quis regular". Contudo "não é fácil determinar um critério para distinguir as normas constitucionais de eficácia plena daquelas de eficácia contida ou limitada. Constitui, mesmo, esse, um problema tormentoso de interpretação das normas constitucionais, e a sua solução se reveste, não obstante, de grande importância prática. 
Apesar de ser caracterizada como uma Carta Magna, soberana, a sua simples existência no plano jurídico não assegura eficácia aos enunciados normativos nela positivados. É, ainda, necessário, conforme mencionado por Hesse (1991, p. 21), que a Constituição exerça sua força normativa.

Diante da necessidade de efetivação das normas constitucionais, bem como da força normativa que deve exercer a Constituição da República Federativa do Brasil, passe-se ao estudo de tais normas segundo Canotilho e Alexy, cujas experiências em Portugal e Alemanha podem contribuir para a efetividade dos Direitos Fundamentais no Brasil.

\section{DIREITOS FUNDAMENTAIS PARA CANOTILHO}

José Joaquim Gomes Canotilho é um jurista português, nascido em 15 de agosto de 1941. É licenciado e doutor em Direito pela Faculdade de Direito da Universidade de Coimbra, onde é Professor catedrático, e professor visitante da Faculdade de Direito da Universidade de Macau. É considerado por muitos como um dos nomes mais relevantes do direito constitucional da atualidade. É atualmente Administrador não Executivo da Fundação Calouste Gulbenkian.

De início, é importante dizer que para Canotilho (2003, p. 105) “os Direitos Fundamentais não são apenas um limite do Estado, são também uma tarefa do Estado. Ao Estado incumbe defendê-los e garanti-los. Não apenas um dado a respeitar, são também uma incumbência a realizar $\left(\mathrm{cfr}\right.$. art. $\left.2^{\circ}\right) "$.

Assim, os Direitos Fundamentais não são um compartilhamento isolado dentro da Constituição, mas fazem parte integrante do conjunto da ordem constitucional, estando organicamente ligados aos outros domínios constitucionais.

Desde logo, os Direitos Fundamentais constituem um dos componentes essenciais da decisão constituinte. E também formam um todo coerente com os outros componentes da decisão constituinte, particularmente o democrático.

A ordem constitucional dos Direitos Fundamentais está necessariamente ligada à "constituição política" e ao princípio democrático que a informa, isto é, à concepção constitucional do Estado de direito democrático. Em suma, "a ordem constitucional dos Direitos Fundamentais é uma parte integrante e integrada da ordem constitucional global" (CANOTILHO, 2008, p. 99). 
Contudo, a Constituição não define os conceitos de "direitos, liberdades e garantias", nem agrupa as várias disposições de acordo com essa trilogia. A distinção entre direitos e liberdades faz-se tradicionalmente com base na posição jurídica do cidadão em relação ao Estado.

As liberdades estariam ligadas ao status negativus e, através dela visa-se defender a esfera jurídica dos cidadãos perante a intervenção ou agressão dos poderes públicos. É por isso que se lhes chama também direitos de liberdade, liberdades-autonomia, liberdades-resistência, direitos negativos, direitos civis, liberdades individuais. Entre elas: direito à vida, direito à integridade pessoal, direito à liberdade e à segurança, direito à identidade.

Sob a designação de direitos, incluem-se tanto os tradicionais direitos naturais inerentes ao homem (direito à vida, à integridade pessoal) - quanto os direitos ligados ao status activus do indivíduo, ou seja, os que visam o indivíduo como participante ativo na vida política. Por isso se designam estes últimos como direitos políticos, liberdades-participação, direitos do cidadão (CANOTILHO, 2008, p. 109).

Os Direitos Fundamentais devem ser compreendidos na sua ligação concreta com uma determinada ordem jurídico-constitucional. Destaca o jurista português:

A constitucionalização dos princípios fundamentais tem um relevante significado
jurídico. Por um lado, eles assumem força normativo-constitucional, dada a superação
definitiva das ideias de Constituição como simples 'complexo de directivas políticas'
e uma vez rejeitada a ideia de que as normas e princípios constitucionais são
meramente programáticos, sem qualquer vinculatividade imediata (CANOTILHO,
1991, p. 73).

Os princípios de Direitos Fundamentais se articulam em termos de complementariedade. Assim, o poder político - com domínio do homem sobre o homem - carece de legitimação, que só pode vir do povo, mas a forma democrática de legitimação exige procedimentos, formas e garantias materiais, de modo a evitar-se uma democracia sem Estado de direito ou um Estado de direito sem democracia.

$\mathrm{Na}$ prática, "as relações de complementariedade, de condicionamento e conjugação entre os princípios fundamentais explicam a necessidade de estabelecer operações de concordância prática entre eles" (CANOTILHO, 2008, p. 75).

O princípio democrático é um princípio jurídico normativo que aponta para a ideia de democracia como forma de vida, como forma de racionalização do processo político e como forma de legitimação do poder, cujos pressupostos materiais podem sintetizar-se em três elementos: juridicidade, constitucionalidade e Direitos Fundamentais. 
A juridicidade significa que a Constituição, ao "decidir-se" por um Estado de direito, procura constituir-se e conformar as estruturas do poder político segundo a medida do direito, isto é, através de um meio de ordenação racional, vinculativamente prescritivo de regras, formas e procedimentos que excluem o arbítrio e a prepotência" (CANOTILHO, 2008, p. 82). Forma e conteúdo justificam-se como meio de ordenação racional, o direito e indissociável da realização da justiça e da efetivação de valores políticos, sociais e culturais.

A constitucionalidade infirma que o Estado de direito pressupõe a existência de uma Constituição, que é uma "ordenação normativa fundamental dotada de supremacia supremacia da Constituição -, e é nesta supremacia da lei constitucional que o "primado do direito' do Estado de direito encontra uma primeira e decisiva expressão" (CANOTILHO, 1991, p. 82).

Por fim, o Estado de direito é um Estado de Direitos Fundamentais, pois assegura ao homem a autonomia perante os poderes públicos, respeito à dignidade da pessoa humana e empenho na defesa e garantia da liberdade, da justiça e da solidariedade (op. cit., p. 83).

Não se trata de definir os princípios fundamentais da República e do Estado, ou os Direitos Fundamentais dos cidadãos, mas, sim, de definir o alcance da própria Constituição como lei fundamental para garantir esses direitos.

Por outro lado, existe também uma conexão material entre a fiscalização da constitucionalidade e a revisão constitucional. Ambos são modos de garantia e de preservação da Constituição (op. cit., p. 235), que servem para dar garantia aos direitos e liberdades fundamentais, não apenas perante o Governo e a Administração, mas também perante o próprio Parlamento (ibidem).

Como se vê, Canotilho conecta os Direitos Fundamentais diretamente com o princípio democrático e faz entender que a sua efetividade se traduz pelos modos de garantia e preservação da própria Constituição. Por ser o princípio democrático um princípio jurídiconormativo, ele aponta para a democracia como forma de vida, de racionalização do processo político e de legitimação do poder.

A efetivação então dos Direitos Fundamentais se dá estabelecendo-se operações de concordância prática entre eles mediante relações de complementariedade, de condicionamento e conjugação, o que pode ser feito mediante o aprimoramento dos mecanismos democráticos e que guarda relação com o que Alexy também busca aperfeiçoar e que será objeto da próxima seção. 


\section{DIREITOS FUNDAMENTAIS PARA ALEXY}

Robert Alexy nasceu em Oldenburg, Alemanha, em 9 de setembro de 1945. É um dos mais influentes filósofos do Direito alemães contemporâneos. Graduou-se em direito e filosofia pela Universidade de Göttingen. Recebeu o título de PhD em 1976, com a dissertação Uma Teoria da Argumentação Jurídica, e a habilitação em 1984, com a Teoria dos Direitos Fundamentais. Atualmente é professor da Universidade de Kiel. Em 2002 foi indicado para a Academy of Sciences and Humanities at the University of Göttingen. Em 2010 recebeu a Ordem do Mérito da República Federal da Alemanha.

Alexy criou a teoria jurídica geral dos Direitos Fundamentais da Constituição alemã com o objetivo de eleger critérios de racionalidade para interpretação e aplicação das normas, em especial, dos Direitos Fundamentais.

Primeiro é importante esclarecer, como o jurista alemão também o faz logo no início de sua principal obra, que é uma teoria de Direitos Fundamentais: não é uma teoria históricojurídica, não é uma filosófico-jurídica. É uma teoria de Direitos Fundamentais.

Segundo que é uma teoria jurídica, isto é, é praticada pela Ciência do Direito em sentido estrito em três dimensões: analítica, porque faz dissecção sistemático-conceitual do direito vigente; empírica, porque parte da cognição do direito positivo e válido, o que inclui a lei, jurisprudência e a efetividade; normativa, porque tem relação com a práxis jurisprudencial, com a fundamentação. O caráter prático da Ciência do Direito revela-se como princípio unificador. Deve ser uma disciplina integradora e multidimensional. Combinar essas três dimensões é condição para a racionalidade da Ciência Jurídica como disciplina prática (ALEXY, 2008, p. $37)$.

E terceiro que é uma teoria geral, ou seja, a teoria se ocupa de todos os Direitos Fundamentais, não de um específico (ibidem). Isso porque a teoria não pode ser apenas unipolar nem combinada, porque não pode ser superficial. Deve ser integrativa. A começar, ser estrutural e empírica-analítica porque perquire a correção e a fundamentação racional dos Direitos Fundamentais (op. cit., p. 43).

Já sobre o local dos Direitos Fundamentais, Alexy (2008, p. 43) destaca que:

Constituições democráticas modernas contêm dois tipos ou categorias de normas. Da primeira categoria fazem parte aquelas normas que constituem e organizam a nação de leis, o poder executivo e a jurisdição, portanto, o estado. No centro está a autorização. Na segunda categoria caem aquelas normas que limitam e conduzem o 
poder estatal. Aqui devem ser mencionados, em primeiro lugar os Direitos Fundamentais.

E sobre o que são propriamente normas de Direitos Fundamentais, Alexy (ibidem) responde de forma simples que, do ponto de vista concreto, "são aquelas normas que são expressas por disposições de Direitos Fundamentais; e disposições de Direitos Fundamentais são os enunciados presentes no texto da Constituição alemã, e somente esses enunciados”.

Adaptando para nossa realidade, delimitam-se os Direitos Fundamentais aos enunciados no art. $5^{\circ}$ da Constituição da República Federativa do Brasil e também outros decorrentes do regime e dos princípios por ela adotados, ou dos tratados internacionais em que a República seja parte, conforme expresso no $\S 3^{\circ}$ do mesmo dispositivo.

Já sobre a estrutura das normas de Direitos Fundamentais, Alexy as classifica como princípios e regras. A diferença entre regras e princípios é qualitativa.

Regras são razões definitivas. "São normas que são sempre satisfeitas ou não satisfeitas. Se uma regra vale, então, deve se fazer exatamente aquilo que ela exige; nem mais nem menos" (ALEXY, 2008, p. 91). A regra contém determinações no âmbito do fático e juridicamente possível. A regra sempre tem que ser cumprida, salvo: se houver uma cláusula de exceção ou se esta regra for declarada inválida.

Então, em caso de conflito de regras deve haver uma cláusula de exceção que exclua a aplicação de uma delas ou haver a invalidade de uma delas. Para invalidar uma regra, utilizamse os critérios da hierarquia, da cronologia ou da especificidade. O importante no conflito de regras é a declaração de invalidade.

Princípios são "mandamentos de otimização, que são caracterizados por poderem ser satisfeitos em graus variados e pelo fato de que a medida devida de sua satisfação não depende das possibilidades fáticas, mas também das possibilidades jurídicas” (op. cit., p. 90). Grosso modo, mandamento é uma ordem. E otimização é um conjunto de técnicas para seleção das melhores alternativas para alcançar fins determinados. Então, princípio é uma ordem para cumprir em sua máxima inteireza o ordenamento jurídico. São normas que determinam que algo seja realizado na maior medida possível, dentro do contexto jurídico e real existentes. São satisfeitos em graus variados. Se não há consenso sobre determinado estado de coisas, então os princípios servem como parâmetros axiológicos. As circunstâncias que possibilitam a satisfação dos graus variados podem ser de ordem fática ou jurídica.

Na colisão de princípios leva-se em conta a dimensão do peso. Então, considerando as circunstâncias do caso, estabelece-se entre os princípios uma relação de precedência 
condicionada. Para a determinação da relação de precedência condicionada se indica em determinado caso concreto as condições sob as quais um princípio precede outro.

Essa natureza do princípio implica a máxima de proporcionalidade, composta por três máximas parciais, ou subprincípios, que expressam a ideia de otimização e servem justamente para resolver a relação de precedência condicionada entre os princípios. São elas: adequação, necessidade e proporcionalidade em sentido estrito.

A adequação guarda relação com a possibilidade fática. Relaciona-se com a "concruência da relação meio-fim, ou seja, com a adequação do meio escolhido para a obtenção do fim pretendido" (MALISKA, 2015, p. 71). Segundo Alexy (2015, p. 19), “consiste em evitar sacrifícios evitáveis. Os sacrifícios, no entanto, são inevitáveis quando os princípios colidem entre si".

A necessidade relaciona-se com o meio menos oneroso das possibilidades fáticas. "O fim não pode ser outro que possa ser alcançado por um meio menos gravoso ao indivíduo" (MALISKA, 2015, p. 271).

E a proporcionalidade em sentido estrito situa-se no sopesamento de possibilidades jurídicas. É o que Alexy (2015, p. 19) chama de lei da ponderação: “Quanto maior o grau de não satisfação ou de restrição de um princípio, maior deverá ser a importância em atender ao outro".

A proporcionalidade em sentido estrito é o que a doutrina nacional brasileira chama erroneamente de princípio da proporcionalidade. Conforme Schier (2015, p. 294), o princípio da proporcionalidade como utilizada pelos tribunais brasileiros, a bem da verdade, garante a "racionalidade fraca" de Alexy.

Em resumo, os princípios: 1- são satisfeitos em graus variados; 2- a medida de sua satisfação depende de possibilidade fáticas e jurídicas; 3- o grau de satisfação não é determinado pelo próprio princípio; e 4- seu objetivo é resguardar direito e servir de parâmetros axiológicos

Segundo Alexy (2008, p. 90), “o ponto decisivo na distinção entre regras e princípios é que princípios são normas que ordenam que algo seja realizado na maior medida do possível dentro das possibilidades fáticas e jurídicas existentes". Regras funcionam no plano da validade. Princípios funcionam no plano do peso.

À guisa de exemplo, na colisão entre o direito da dignidade da pessoa humana e direito à vida, quando se conjectura o emprego de tortura em um homem que sequestrou um avião para lançá-lo em local público, Alexy (2015, p. 22) comenta: 
A prática de tortura, na hipótese de uma bomba nuclear já ativada, interfere, sem dúvida, na dignidade da pessoa humana. No outro exemplo, aceitar a morte dos passageiros é obviamente uma profunda intervenção em seu direito à vida. Se isso é também uma intervenção em seu direito à dignidade humana (...) é questão que permanece em aberto. O ponto decisivo é que, em ambos os casos, a questão se a intervenção é justificada depende essencialmente da confiabilidade de inúmeras suposições (...).

O tribunal alemão se posicionou assim:

\begin{abstract}
As incertezas [...] necessariamente afetam o prognóstico sobre quanto tempo de vida ainda têm as pessoas a bordo de um avião, que foi transformado em uma arma de ataque, e se ainda há uma chance de salvá-las. Por essa razão, normalmente, não será possível fazer uma análise confiável, que conclua que as vidas dessas pessoas já estão de qualquer forma perdidas (ALEXY, 2015, p. 22).
\end{abstract}

Com efeito, a teoria dos Direitos Fundamentais de Robert Alexy busca desenvolver uma argumentação jurídica racional de ponderação. As alternativas contrárias à ponderação são relegadas para algo como "intuicionismo". Para o professor alemão (ALEXY, 2015, p. 36), argumentação é uma expressão da racionalidade; intuicionismo é confissão de irracionalidade.

Vê-se então que para Alexy existem regras e princípio de Direitos Fundamentais. Em caso de conflito de regras, resolve-se pela exceção ou invalidade de uma delas. Já em caso de colisão de princípios, resolve-se pela aplicação das três submáximas da adequação, necessidade e proporcionalidade em sentido estrito.

Desse modo, a contribuição de Alexy para a efetivação dos Direitos Fundamentais é a tentativa de racionalizar critérios de ponderação para aplicação dos Direitos Fundamentais, mediante sua fórmula de peso para estabelecer uma relação de precedência condicionada que indica em determinado caso concreto as condições sob as quais um princípio precede outro.

\title{
5 CONSIDERAÇÕES FINAIS
}

Em razão dessas considerações, viu-se a importância em operar a Constituição da República Federativa do Brasil a partir da política e principiologia constitucional. A Constituição é para o Estado a norma de maior importância dentre as normas do ordenamento jurídico. Nela constam a forma de organização do Estado e as garantias, liberdades e Direitos Fundamentais dos cidadãos.

Delimitam-se como Direitos Fundamentais no Brasil os contidos nos enunciados no art. $5^{\circ}$ da vigente Constituição da República Federativa do Brasil e também outros decorrentes do 
regime e dos princípios por ela adotados, ou dos tratados internacionais em que a República seja parte, conforme expresso no $\S 3^{\circ}$.

Para o jurista português Canotilho, a ordem constitucional dos Direitos Fundamentais está necessariamente ligada ao princípio democrático que a informa, isto é, à concepção constitucional do Estado de direito democrático.

Sua contribuição apta a ser transplantada para a efetividade dos Direitos Fundamentais no Brasil se traduz pelos modos de garantia e preservação da própria Constituição. Por ser o princípio democrático um princípio jurídico-normativo, ele aponta para a democracia como forma de vida, de racionalização do processo político e de legitimação do poder.

A efetivação então dos Direitos Fundamentais se dá estabelecendo-se operações de concordância prática entre eles mediante relações de complementaridade, de condicionamento e conjugação das normas com o aperfeiçoamento dos mecanismos da democracia.

Já para o jurista alemão Alexy, o Estado ideal é da combinação entre liberdade e proteção social. A justiça pode fazer isso por intermédio da teoria da ponderação. Se o parlamento não é capaz de proteger os Direitos Fundamentais, o Judiciário deve fazê-lo.

E, para que o Judiciário possa fazê-lo, Alexy busca desenvolver uma argumentação jurídica racional de ponderação, visando evitar "intuicionismo" para decidir mediante a sugestão de parâmetros axiológicos baseados em circunstâncias que possibilitam a satisfação dos graus variados de ordem fática ou jurídica.

Para o alemão podem existir regras e princípios de Direitos Fundamentais. Em caso de conflito de regras, resolve-se pela exceção ou invalidade de uma delas. Já em caso de colisão de princípios, resolve-se pelas três submáximas da adequação, necessidade e proporcionalidade em sentido estrito.

Sua contribuição para a efetivação dos Direitos Fundamentais é a tentativa de racionalizar critérios de ponderação na aplicação dos Direitos Fundamentais, mediante sua fórmula de peso visando estabelecer uma relação de precedência condicionada que indica em determinado caso concreto as condições sob as quais um princípio precede outro.

Retoma-se o problema enfrentado da falta de efetividade das normas de Direitos Fundamentais da Constituição da República Federativa do Brasil. E confirma-se a hipótese de que a efetividade dos Direitos Fundamentais depende da interpretação e aplicação dada pelos operadores jurídicos, no que Canotilho e Alexy podem contribuir, haja vista que o primeiro cuida de conectar os Direitos Fundamentais essencialmente com os mecanismos da democracia; 
e o segundo trabalha a fórmula da ponderação no caso de conflito de regras e de colisão de princípios que envolvem os Direitos Fundamentais.

Ambos as contribuições servem para a realidade brasileira, levando em conta a similaridade das Constituições e a previsão dos Direitos Fundamentais. Obviamente o processo histórico a que estão submetidos impõe admitir ambos os estudos de forma sempre provisória e ser reanalisado conforme os avanços dos tempos modernos, pois precedentes e critérios não são tabus, mas devem ser aprimoradas conforme as circunstâncias fáticas e históricas que se apresentam.

\section{REFERÊNCIAS}

ALEXY, Robert. A dignidade humana e a proporcionalidade. Dignidade humana, direitos sociais e não-positivismo inclusivo. Florianópolis: Qualis, 2015.

ALEXY, Robert. Constitucionalismo Discursivo. Tradução de Luís Afonso Heck. Porto Alegre: Livraria do Advogado Editora, 2007.

ALEXY, Robert. Teoria dos Direitos Fundamentais. Tradução de Vergílio Afonso da Silva. São Paulo: Malheiros, 2008.

BARROSO, Luís Roberto. Curso de Direito Constitucional Contemporâneo. Os conceitos fundamentais e a construção do novo modelo. 3. ed. São Paulo: Saraiva, 2011.

BARROSO, Luiz Roberto. Neoconstitucionalismo e Constitucionalização do Direito. (O Triunfo Tardio do Direito Constitucional no Brasil). Revista Eletrônica sobre a Reforma do Estado (RERE), Salvador, Instituto Brasileiro de Direito Público, n. 9, março/abril/maio 2007. Disponível em: <http://www.direitodoestado.com.br/radae.asp>. Acesso em: 13 jul. 2016.

BOBBIO, Norberto. A Era dos Direitos. 8 reimp. Rio de Janeiro: Elsevier, 2004.

BONAVIDES, Paulo. Jurisdição constitucional e legitimidade (algumas observações sobre o Brasil). Estudos Avançados, São Paulo, v. 18, n. 51, agosto. 2004. Disponível em: $<$ http://www.scielo.br/scielo.php?script=sci_arttext\&pid=S0103-

40142004000200007\&lang=pt>. Acesso em: 13 jul. 2016. 
BRASIL. Constituição (1988). Disponível em: <http://www.planalto.gov.br/ccivil_03/constituicao/ConstituicaoCompilado.htm>. Acesso em: 13 jul. 2016.

CANOTILHO, José Joaquim Gomes. Direito Constitucional e Teoria da Constituição. 7. ed. 9 reimp. Coimbra: Almedina, 2003.

CANOTILHO, José Joaquim Gomes. Estudos sobre Direitos Fundamentais. 1. ed. brasileira, 2. ed. portuguesa. Coimbra/São Paulo: Coimbra/Revista dos Tribunais, 2008.

CANOTILHO, José Joaquim Gomes. Fundamentos da Constituição. Coimbra, Portugal: Coimbra Editora, 1991.

DESCARTES, René. Discurso do Método. Trad. Maria Ermantina Galvão G. Pereira. São Paulo: Martins Fontes, 1999.

FERRAJOLI, Luigi. Por uma carta dos bens fundamentais. Seqüência, Florianópolis, v. 31, n. 60, p.29-73, jul. 2010. Disponível em: <http://www.periodicos.ufsc.br/index.php/sequencia/article/view/21777055.2010v31n9/1506 6>. Acess: em 13 jul. 2016.

HESSE, Konrad. A Força Normativa da Constituição. Tradução de Gilmar Ferreira Mendes. Porto Alegre: Sergio Antonio Fabris Editor, 1991.

LASSALLE, Ferdinand. A essência da Constituição. 4. ed. Rio de Janeiro: Lumen Juris, 1998.

MALISKA, Marcos Augusto. O princípio da proporcionalidade e os direitos fundamentais prestacionais. Dignidade humana, direitos sociais e não-positivismo inclusivo. Florianópolis: Qualis, 2015.

MIRANDA, Jorge. Teoria do Estado e da Constituição. 3. ed. Rio de Janeiro: Forense, 2011.

PASOLD, Cesar Luiz. Metodologia da Pesquisa Jurídica: Teoria e Prática. 13. ed. rev. atual. e ampl. Florianópolis: Conceito Editorial, 2015.

SCHIER, Paulo Ricardo. A objeção central ao princípio da proporcionalidade no contexto do constitucionalismo brasileiro. Dignidade humana, direitos sociais e não-positivismo inclusivo. Florianópolis: Qualis, 2015. p. 294. 
SILVA, José Afonso da. Aplicabilidade das Normas Constitucionais. 3. ed. São Paulo: Malheiros Editores, 1998.

THE EFFECTIVENESS OF FUNDAMENTAL RIGHTS ACCORDING TO

CANOTILHO AND ALEXY

\begin{abstract}
This cientific paper investigates how scientific studies of the Portuguese jurist José Joaquim Gomes Canotilho and German jurist Robert Alexy can contribute to the realization of Fundamental Rights provided for in the current Constitution of the Federative Republic of Brazil. Although positivized the Constitution, the effectiveness of Fundamental Rights on the interpretation and application given by lawyers, there appear the importance of the contribution of both authors, when they face the same problems in the constitution of their countries. In the first part was characterized positivization of Fundamental Rights in the current Constitution of the Federative Republic of Brazil. The second was treated theme approach with the democratic principle developed by Canotilho. The third part was presented the theory of Fundamental Rights of Alexy. It concluded adapting the main ideas of both the Brazilian reality in order to contribute to the realization of Fundamental Rights. The research is justified by the importance of the theme for the contemporary, especially on the need for enforcement of Fundamental Rights. The work was developed under inductive method. The research was literature and documents.
\end{abstract}

Keywords: Fundamental Rights. Effectiveness. Rules. Principles. Democracy. 